\title{
Reproducibility of Regional DEXA Examinations of Abdominal Fat and Lean Tissue
}

\author{
Kaj Tallroth ${ }^{a}$ Jyrki A. Kettunen ${ }^{a}$ b Urho M. Kujala ${ }^{c}$ \\ ${ }^{a}$ ORTON Orthopaedic Hospital, ORTON Foundation, ${ }^{b}$ Arcada University of Applied Sciences, \\ Helsinki, 'Department of Health Sciences, University of Jyväskylä, Jyväskylä, Finland
}

\section{Key Words}

Obesity $\cdot$ DEXA $\cdot$ Abdominal fat $\cdot$ Abdominal muscles $\cdot$ Reproducibility

\begin{abstract}
Objective: The aim of this study was to develop and test the validity of a new repeatable method to delimit abdominal areas for follow-up of fat mass (FM) and lean tissue mass (LM) in DEXA examinations. Methods: 37 male volunteers underwent two DEXA examinations. Total body FM and LM measurements and corresponding abdominal measurements in a carefully defined region were calculated from the first scan. After repositioning of the subjects and a second scan, the delimited region was copied and the abdominal tissues re-calculated. Results: The mean LM of the abdominal area was $2.804 \mathrm{~kg}$ (SD 0.556), and the mean FM was $1.026 \mathrm{~kg}$ (SD 0.537). The intra-class correlation coefficient for the repeated abdominal LM, FM, and LM/FM ratio measurements was 0.99 . The mean difference (bias) for the repeated abdominal LM measurements was $-13 \mathrm{~g}$ (95\% confidence interval (CI) -193.0 to 166.8), and for the repeated abdominal FM measurements it was $-35 \mathrm{~g}$ (95\% CI -178.9 to 108.5). Conclusions: The results indicate that regional DEXA is a sensitive method with excellent reproducibility in the measurements of the abdominal fat and lean tissues. The method may serve as a useful tool for evaluation and follow-up of various dietary and training programmes.
\end{abstract}

Copyright (c) 2013 S. Karger GmbH, Freiburg

\section{Introduction}

In recent years, the prevalence of overweight and obesity has increased dramatically in both the industrialized and developing countries [1]. This worldwide epidemic of obesity will shortly lead to a situation in which the number of overfed individuals will surpass that of 
Tallroth et al.: Reproducibility of Regional DEXA Examinations of Abdominal Fat and Lean Tissue

malnourished individuals [2]. Obesity represents one of the five major health risks in modern societies [3], as it is associated with increased risk for morbidity from a great number of diseases [4].

Abdominal fat is composed of abdominal subcutaneous fat and intra-abdominal visceral fat. It has been stated that visceral adipose tissue is an endocrine organ and plays an important role in energy metabolism through different adipocytokines that have hormonal and inflammatory functions [5, 6]. Visceral fat accumulation has been shown to be associated with higher risk for coronary artery disease, blood pressure, metabolic syndrome, insulin resistance and low-grade inflammation [1, 4, 7-10].

Several anthropometric variables such as abdominal diameter, skinfold thickness, waistto-height ratio, waist-to-hip ratio and waist circumference have been commonly used in large epidemiological studies as they are simple and inexpensive [11, 12]. BMI (in $\mathrm{kg} / \mathrm{m}^{2}$ ) has become the by far most common indicator of obesity or being overweight, although it only describes the ratio between total body mass and height, and not body fat content.

DEXA is widely used for measurement of total body composition, bone mineral content (BMC), lean tissue mass (LM) and fat tissue mass (FM). In the total body composition measurement the radiation exposure is minimal, equivalent to $0.1 \mu \mathrm{Gy}$ [13]. This technique is frequently used in obesity-related research [14-17] and when evaluating the effect of surgery for obesity $[17,18]$. Recent DEXA computer software can automatically calculate abdominal fat in regions according to bony anatomical landmarks $[1,13,19,20]$. Regions on DEXA images may be set also with great accuracy manually [21]. This alternative method has been used in several analyses of abdominal fat studies [15, 22-24]. For follow-up studies of extremities and trunk, one can define a region of interest (ROI) in one examination and then copy it to a later examination of the same subject $[25,26]$.

In longitudinal obesity prevention investigations, it is crucial to have a simple method to estimate accumulation of abdominal fat as this is strongly related to the development of metabolic complications and increased cardio-metabolic risk. Hence, our working aim was to develop and test a novel repeatable method to delimit an abdominal area for regional followup DEXA measurements. The specific aim of the present study was to assess the repeatability and validity of DEXA scanning for abdominal fat and lean tissue measurements.

\section{Subjects and Methods}

We analysed two repeated DEXA scans of 37 healthy male volunteers and estimated total body composition and regional tissue composition in a well-defined abdominal area. The study was carried out at ORTON Orthopaedic Hospital, Helsinki. The aim of the study was explained to the participants, and their written consent to participation was obtained. The Ethics Committee of the Hospital District of Helsinki and Uusimaa approved the study protocol.

\section{DEXA Examinations}

For the DEXA examinations, a narrow fan-beam Lunar Prodigy densitometer (GE Lunar Corporation, Madison, WI, USA) was used. This scanner incorporates a constant potential X-ray source at $76 \mathrm{kV}$ and a K-edge filter (cerium) to achieve a congruent beam of stable dual-energy radiation, $38 \mathrm{keV}$ and $70 \mathrm{keV}$. The total body scanning time was 6-7 min. As the X-ray beam passes through the subject, the beam undergoes attenuation by the tissues. The Lunar Prodigy software version 8.80 uses a series of complex algorithms to calculate bone density, bone mass, LM and FM in the total body and for anatomical regions. According to the manufacturer's instructions, the recommended weekly calibrations of the DEXA scanner with different phantoms were performed daily to enhance the reproducibility and stability of the data.

For this study, two total body composition DEXA scans were performed on each participant. After the first scanning in the supine position, the subjects were asked to stand up and then to lie down again to be repositioned for the second repeat scan. An experienced radiology technologist, specially trained for these 
Tallroth et al.: Reproducibility of Regional DEXA Examinations of Abdominal Fat and Lean Tissue

Fig. 1. The manually defined region for the abdominal DEXA measurement (see text for description of the borders).

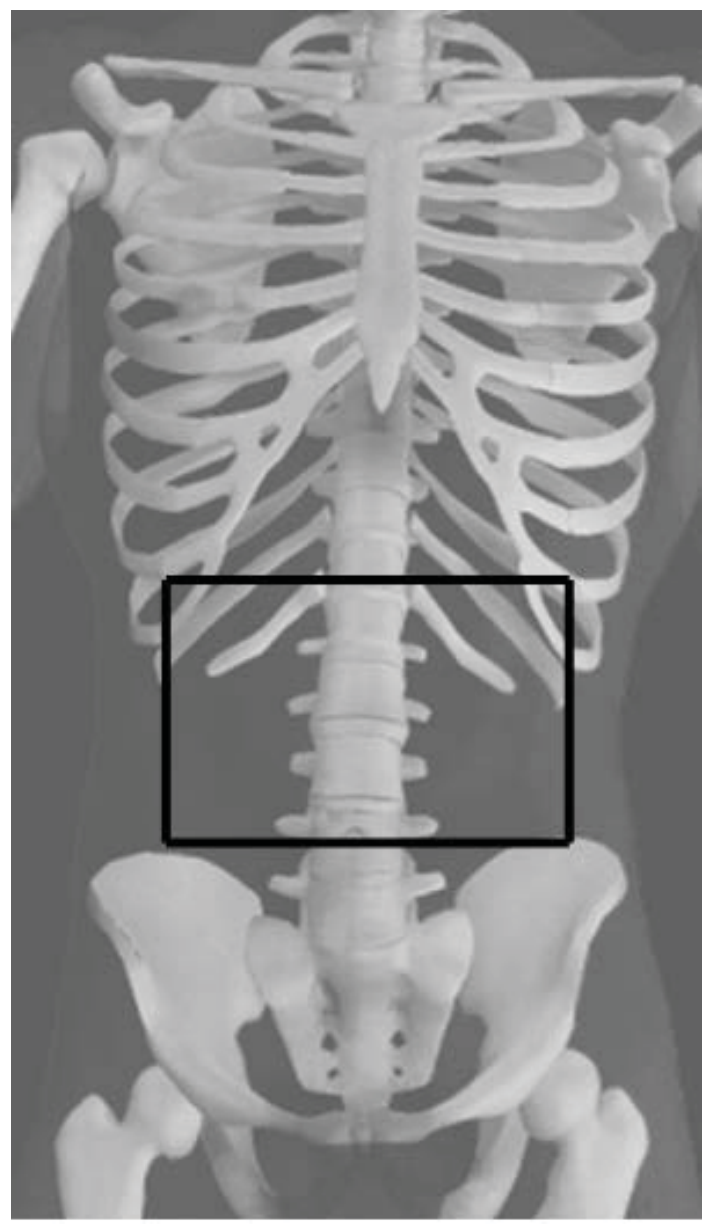

examinations, performed the DEXA examinations. For total body and extremity composition measurements we have earlier reported excellent repeatability [21]. In this present study we manually set a ROI in the first scan for the regional measurements of the abdomen. The ROI was delimited on the basis of bony landmarks, cranially by the upper end plate of the first lumbar vertebra, laterally by the ribs at this level and caudally by the pelvis (fig. 1). After calculation of the tissue composition of the abdomen the ROI was copied with the compare feature method $[25,27]$ to the second scan of the same individual for measurements from this examination, and for the comparison and repeatability calculations of the two examinations. An experienced musculoskeletal radiologist, KT, did all the ROI settings.

The regional composition of the abdomen for each subject was calculated automatically by the DEXA scanner. The results were reported as kilograms for LM and FM. BMD was measured in $\mathrm{g} / \mathrm{cm}^{2}$. The percentage ratio of fat, muscle and bone was calculated for every subject in the two examinations.

\section{Statistical Analysis}

Reliability of the measurements was evaluated by calculating the intra-class correlation coefficient (ICC) [28] with a one-way random model. The calculations of the standard deviation(SD) of the measurement errors between repeated measurements were based on the analysis of variance. We also analysed the agreement between the repeated measurements of LM and FM with the Bland-Altman method [9]. In figures 2 and 3, the solid line represents the mean of the difference (bias) in the repeated measurements, and the dashed lines represent the 95\% confidence intervals (CI) for the mean difference. The analyses were performed using the Statistical Package for the Social Sciences 17.0 (Norusis/SPSS, Inc., Chicago, IL, USA). 
Tallroth et al.: Reproducibility of Regional DEXA Examinations of Abdominal Fat and Lean Tissue

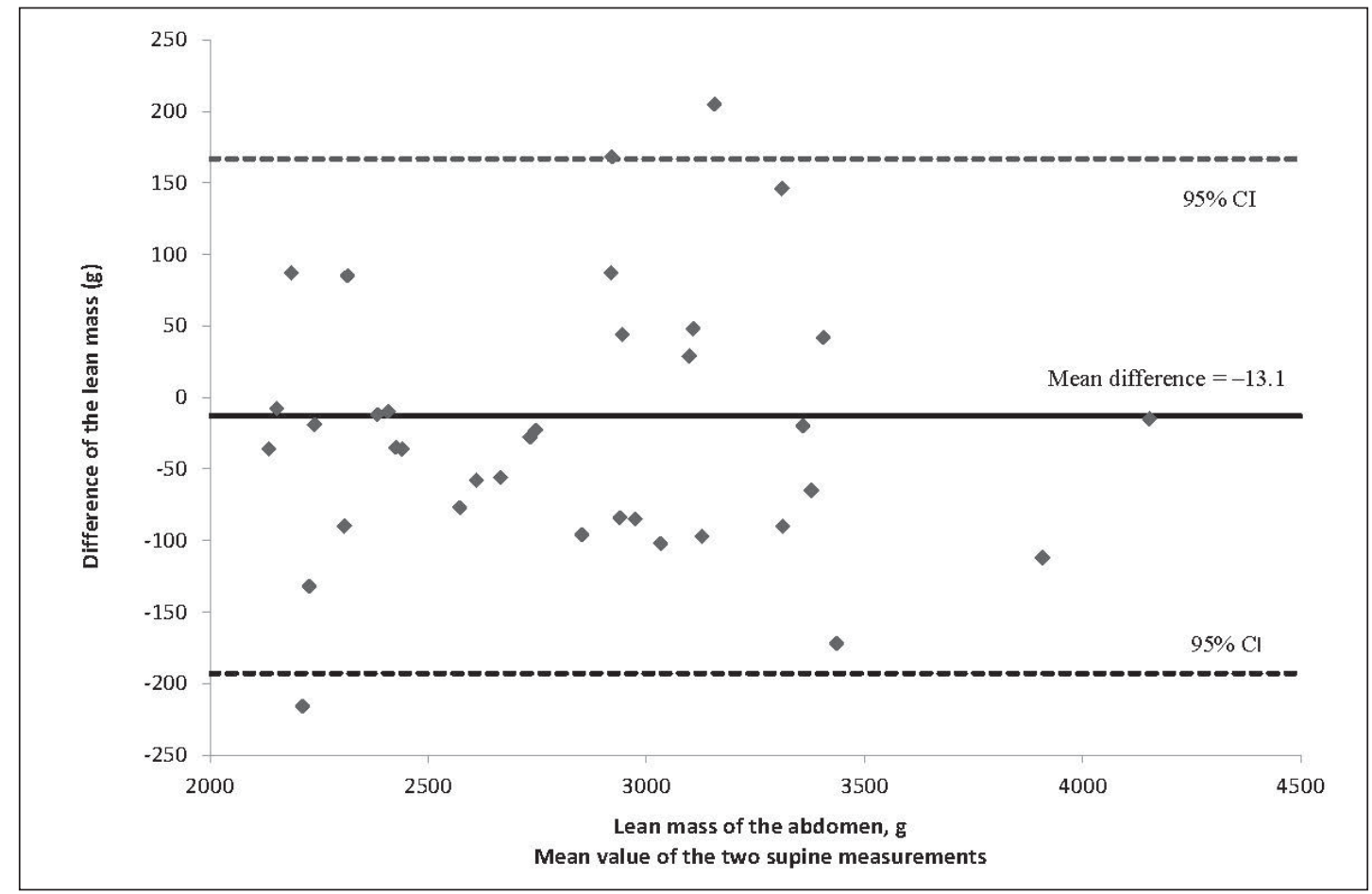

Fig. 2. Differences against mean for lean mass measurements of the abdomen with manually set regions in two subsequent scans in supine position in 37 individuals.

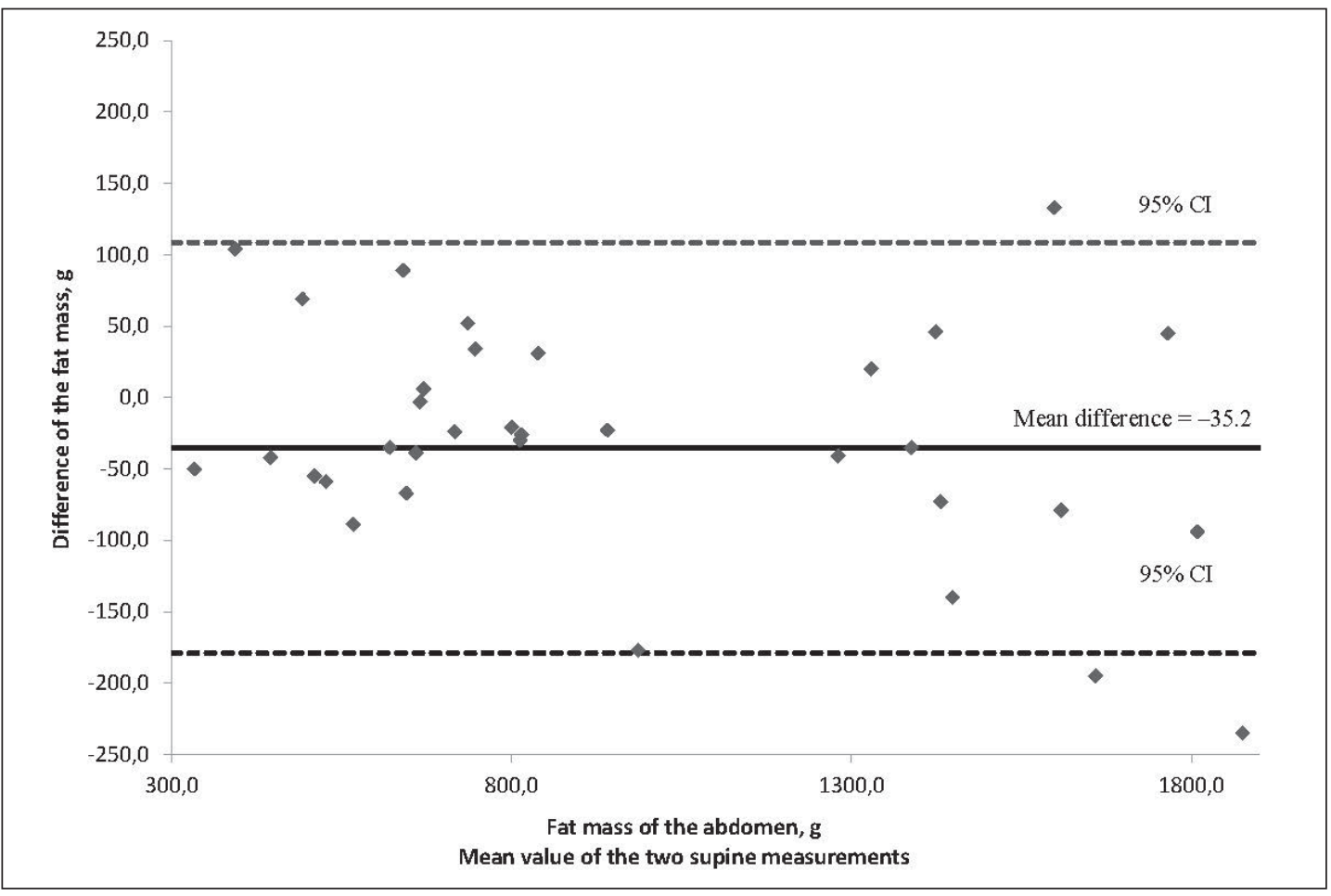

Fig. 3. Differences against mean for fat mass measurements of the abdomen with manually set regions in two subsequent scans in supine position in 37 individuals. 
Tallroth et al.: Reproducibility of Regional DEXA Examinations of Abdominal Fat and Lean Tissue

Table 1. Tissue composition measurements of the abdominal region using manually set regions in 37 subjects scanned twice

\begin{tabular}{|c|c|c|c|c|c|}
\hline \multirow[t]{2}{*}{ Location of measurement } & \multicolumn{2}{|c|}{ First measurement } & \multicolumn{2}{|c|}{ Second measurement } & \multirow{2}{*}{$\begin{array}{l}\text { First vs. second } \\
\text { measurement, ICC }\end{array}$} \\
\hline & mean & SD & mean & SD & \\
\hline \multicolumn{6}{|l|}{ Total body } \\
\hline Lean mass, kg & 59.204 & 6.503 & & & \\
\hline Fat mass, kg & 19.678 & 7.159 & & & \\
\hline Lean mass / fat mass ratio & 3.43 & 1.38 & & & \\
\hline \multicolumn{6}{|l|}{ Abdominal region } \\
\hline Lean mass, kg & 2.804 & 0.556 & 2.793 & 0.506 & 0.99 \\
\hline Fat mass, kg & 1.026 & 0.537 & 0.999 & 0.520 & 0.99 \\
\hline Lean mass / fat mass ratio & 3.61 & 2.40 & 3.69 & 2.50 & 0.99 \\
\hline
\end{tabular}

$\mathrm{SD}=$ Standard deviation; $\mathrm{ICC}=$ intraclass correlation coefficient.

\section{Results}

Repeated DEXA scans of 37 healthy Finnish men were included in this study. The age of the subjects ranged from 22 to 61 years (mean age 45.1 years), and the mean BMI ranged from 17.8 to $33.9 \mathrm{~kg} / \mathrm{m}^{2}$ (mean $26.2 \mathrm{~kg} / \mathrm{m}^{2}$ ) at the time of the examinations.

Table 1 shows the LM and FM tissue values for the first total body scanning and the mean for both DEXA measurements of the abdominal region. The SD of the measurement error between repeated LM measurements was $56.7 \mathrm{~g}$ and the corresponding SD between FM measurements was $64.5 \mathrm{~g}$. The ICCs for the repeated abdominal LM, FM and for the LM/FM ratio measurements were excellent. The mean differences and the limits of the agreements between the repeated measurements of tissues of the abdominal region are shown in figures 2 and 3. In three of the subjects the difference between the repeated LM and FM measurements was outside the $95 \%$ CI.

The mean relative whole body fat composition in our subjects was $23.3 \%$, and on average $5.2 \%$ of the whole body FM was located in the abdominal area, according to our measurements. The correlation (Pearson's correlation coefficient, $r$ ) between BMI and whole body fat composition was $0.69(\mathrm{p}<0.001)$. Moreover, the correlation between whole body FM $(\mathrm{kg})$ and abdominal region FM (kg) was $0.88(\mathrm{p}<0.001)$.

\section{Discussion}

Due to the increasing worldwide occurrence of obesity and resulting medical complications, methods of monitoring body fat, and especially abdominal fat, are important. In several studies it has been stated that the DEXA methodology can determine total body LM and FM with small precision error and good reproducibility. The total body precision errors have been as low as below $1.5 \%$ for FM and $1.5 \%$ for LM $[13,21,30]$. DEXA offers quickness of scan (only 6-7 min for total body assessment) and clinical convenience, and involves a minimal radiation dose [13].

The most common way to treat obese people is to encourage them to reduce their total body weight by increasing their physical activity and modifying their eating habits. Several DEXA studies have shown that by strength training it is also possible to effectively and signif- 
Tallroth et al.: Reproducibility of Regional DEXA Examinations of Abdominal Fat and Lean Tissue

icantly reduce fat mass in specific regions such as the trunk $[23,26,31,32]$ and at the same time increase lean tissue mass $[23,24,26,31]$.

Many of the regional abdominal DEXA studies have used ROIs defined automatically by the scanner's software with various accuracies. Hetland et al. [19] reported precision errors for 11 subjects measured twice approximately 1 week apart: FM $0.012-0.069 \mathrm{~kg}$, LM $0.051-$ $0.13 \mathrm{~kg}$. Mazess and co-workers [13] found slightly higher precision errors in regional measurements than in total body measurements. In a clinical heart study with DEXA evaluation of truncal fat and lean mass, Bestetti et al. [1] assessed the coefficient of variation of the scanner as $<1 \%$ for measures obtained in vivo. Manually delineated regions of the abdomen have been reported in the studies of Jensen et al. [22], Ferreira et al. [15] and Fleck et al. [24], although without information about the precision of the DEXA examinations.

Both Hologic (Bedford, MA, USA) and Lunar have introduced a compare feature into the software that allows analyses of repeated scans by comparison with the original scan. An area is defined manually on one examination and then copied and manually placed on another DEXA image of another examination of the same individual. This compare feature has been used with a Hologic scanner by Chilibeck et al. [33] in analyses of the precision of regional LM and FM measurements. The DEXA examinations were performed on a group of 21 women but on different occasions. They concluded that the method error of the abdominal measurements expressed as a coefficient of variation (CV) was $2.0 \%$ for LM and $4.4 \%$ for FM. The reproducibility of this method on trunk FM and LM measurements has not previously been studied with the use of a Lunar Prodigy scanner.

Our findings, obtained in a group of healthy men, showed that it is possible to copy a specific manually defined abdominal area from one DEXA examination to another with great precision. This in turn made it possible to evaluate values for abdominal FT and LM with excellent reproducibility in repeat examinations. In general, there was a relatively good correlation with the FM of the marked-off area and total body fat. However, we observed in some cases that regional measurements can distinguish between superfluous abdominal FM and general overweight which is not possible with BMI or weight measurements. We have also observed a high BMI while abdominal FM has been scarce, indicating that the high BMI can be due to high muscle mass. In studies comparing BMI and DEXA indexes of FM and LM, DEXA-derived measures have been better predictors of cardio-vascular and diabetes risk factors [34, 35] and superior to BMI to identify alterations in FM associated with changes of lifestyle in early adulthood [36].

For this study we designed a ratio (LM/FM) based on the abdominal LM and FM values which both showed excellent accuracy in the measurements. This ratio, like most ratios, is affected by both components. In the follow-up of individuals undergoing for example rehabilitation of low back problems, including abdominal and paraspinal muscle training concurrent with a strict diet, it is presumable that the muscle mass increase and the fat reduction additively affect the ratio. In our repeated measurements the ratio demonstrated excellent reproducibility.

There are some limitations of our study that need to be mentioned. Our subjects, by necessity, consisted of a convenient sample of hospital employees and may not be representative for the general population. All subjects were healthy white adult males of normal weight. A change in body shape affects the contact area on the table and may influence the scan results. In very obese subjects in particular, an abdominal skinfold may move or a pot belly may roll to the side. Due to the small sample size, the statistical power to study this phenomenon in more detail was not available. Also DEXA measurements include some limitations. Sood et al. [37] have pointed out that DEXA-assessed LM is not entirely fat-free because there is small amount of metabolically active ectopic fat in the skeletal muscles and viscera. Furthermore, the water content of LM may vary which DEXA software does not 
Tallroth et al.: Reproducibility of Regional DEXA Examinations of Abdominal Fat and Lean Tissue

register. These aspects had no significance in the present study in which the repeat scans were performed during the same session. In future, these aspects can be evaluated by magnetic resonance spectroscopy.

In conclusion, there is an increasing need to accurately measure abdominal adipose tissue because of the association between increased abdominal fat and health risks. The results of the present study indicate that a regional DEXA of the abdomen is a sensitive method with excellent reproducibility for the determination of small changes in fat and lean tissue. Although this novel method seems to be suitable for the evaluation and follow-up of various dietary and training programmes aimed at decreasing weight and strengthening the abdominal muscles, further studies are needed to investigate the precision of this method in severely obese population.

\section{Disclosure Statement}

The authors declared no conflicts of interest.

\section{References}

1 Bestetti A, Castini D, Bigi R, Maioli C, Lombardi F, Gregori D, Cornalba G: Truncal fat determined by dual-energy $\mathrm{X}$-ray absorptiometry is an independent predictor of coronary artery disease extension. Eur J Cardiovasc Prev Rehabil 2008;15:428-433.

-2 Tanumihardjo SA, Anderson C, Kaufer-Horwitz M, Bode L, Emenaker NJ, Haqq AM, Satia JA, Silver HJ, Staddler DD: Poverty, obesity, and malnutrition: an international perspective recognizing the paradox. J Am Diet Assoc 2007;107:1966-1972.

3 World Health Organization: Health Report 2005. Geneva, WHO, 2005.

4 Blüher M: Adipose tissue dysfunction in obesity. Exp Clin Endocrinol Diabetes 2009;117:241-250.

5 Berggren JR, Hulver MW, Houmard JA: Fat as an endocrine organ: influence of exercise. J Appl Physiol 2005; 99:757-764.

6 Phillips LK, Prins JB: The link between abdominal obesity and the metabolic syndrome. Curr Hypertens Rep 2008;10:156-164.

7 Larsson B, Svärdsudd K, Welin L, Wilhelmsen L, Björntorp P, Tibblin G: Abdominal adipose tissue distribution, obesity, and risk of cardiovascular disease and death: 13 year follow up of participants in the study of men born in 1913. Br Med J (Clin Res Ed) 1984;12:1401-1404.

-8 Sironi AM, Gastaldelli A, Mari A, Ciociaro D, Positano V, Buzzigoli E, Giannessi D, Lombardi M, Mari A, Ferrannini E: Visceral fat in hypertension: influence on insulin resistance and beta-cell function. Hypertension 2004;44: 127-133.

-9 Ludescher B, Machann J, Eschweiler GW, Vanhöfen S, Maenz C, Thamer C, Claussen CD, Schick F: Correlation of fat distribution in whole body MRI with generally used anthropometric data. Invest Radiol 2009;44:712719.

10 Mathieu P, Poirier P, Pibarot P, Lemieux I, Després JP: Visceral obesity: the link among inflammation, hypertension, and cardiovascular disease. Hypertension 2009;53:577-584.

11 Heymsfield SB, Tighe A, Wang ZM: Nutritional assessment by anthropometric and biochemical methods; in Shils ME, Olson JA, Shike M (eds): Modern Nutrition in Health and Disease, 8th ed. Malvern, Lea \& Febiger, 1994, pp 812-841.

12 Nordhamn K, Södergren E, Olsson E, Karlström B, Vessby B, Berglund L: Reliability of anthropometric measurements in overweight and lean subjects: consequences for correlations between anthropometric and other variables. Int J Obes Relat Metab Disord 2000;24:652-657.

13 Mazess RB, Barden HS, Bisek JP, Hanson J: Dual-energy x-ray absorptiometry for total-body and regional bonemineral and soft-tissue composition. Am J Clin Nutr 1990;51:1106-1112.

14 Volek JS, Gomez AL, Love DM, Weyers AM, Hesslink R Jr, Wise JA, Kraemer WJ: Effects of an 8-week weight-loss program on cardiovascular disease risk factors and regional body composition. Eur J Clin Nutr 2002;56:585592.

15 Ferreira I, Snijder MB, Twisk JW, van Mechelen W, Kemper HC, Seidell JC, Stehouwer CD: Central fat mass versus peripheral fat and lean mass: opposite (adverse versus favorable) associations with arterial stiffness? The Amsterdam Growth and Health Longitudinal Study. J Clin Endocrinol Metab 2004;89:2632-2639.

16 Frisard MI, Greenway FL, Delany JP: Comparison of methods to assess body composition changes during a period of weight loss. Obes Res 2005; 13:845-854. 
Tallroth et al.: Reproducibility of Regional DEXA Examinations of Abdominal Fat and Lean Tissue

17 Coupaye M, Bouillot JL, Poitou C, Schutz Y, Basdevant A, Oppert JM: Is lean body mass decreased after obesity treatment by adjustable gastric banding? Obes Surg 2007;17:427-433.

-18 Olbers T, Björkman S, Lindroos A, Maleckas A, Lönn L, Sjöström L, Lönroth H: Body composition, dietary intake, and energy expenditure after laparoscopic Roux-en-Y gastric bypass and laparoscopic vertical banded gastroplasty: a randomized clinical trial. Ann Surg 2006;244:715-722.

19 Hetland ML, Haarbo J, Christiansen C: Regional body composition determined by dual-energy X-ray absorptiometry. Relation to training, sex hormones, and serum lipids in male long-distance runners. Scand J Med Sci Sports 1998;8:102-108.

-20 Skalsky AJ, Abresch RT, Han JJ, Shin CS, McDonald CM: The relationship between regional body composition and quantitative strength in facioscapulohumeral muscular dystrophy (FSHD). Neuromuscul Disord 2008;18: 73-80.

21 Lohman M, Tallroth K, Kettunen JA, Marttinen MT: Reproducibility of dual-energy x-ray absorptiometry total and regional body composition measurements using different scanning positions and definitions of regions. Metabolism 2009;58:1663-1668.

22 Jensen MD, Kanaley JA, Reed JE, Sheedy PF: Measurement of abdominal and visceral fat with computed tomography and dual-energy x-ray absorptiometry. Am J Clin Nutr 1995;61:274-278.

23 Nindl BC, Harman EA, Marx JO, Gotshalk LA, Frykman PN, Lammi E, Palmer C, Kraemer WJ: Regional body composition changes in women after 6 months of periodized physical training. J Appl Physiol 2000;88:22512259.

24 Fleck SJ, Mattie C, Martensen HC III: Effect of resistance and aerobic on regional body composition in previously recreationally trained middle-aged women. Appl Physiol Nutr Metab 2006;31:261-270.

25 Calder AW, Chilibeck PD, Webber CE, Sale DG. Comparison of whole and split weight training routines in young women. Can J Appl Physiol 1994;19:185-199.

26 Chilibeck PD, Calder A, Sale DG, Webber CE: Twenty weeks of weight training increases lean tissue mass but not bone mineral mass or density in healthy, active young women. Can J Physiol Pharmacol 1996;74:11801185.

27 Chilibeck PD, Calder AW, Sale DG, Webber CE: A comparison of strength and muscle mass increases during resistance training in young women. Eur J Appl Physiol Occup Physiol 1998;77:170-175.

28 Shrout PE, Fleiss JL: Intraclass correlations: uses in assessing rater reliability. Psychol Bull 1979;86,420-428.

29 Bland JM, Altman DG: Statistical methods for assessing agreement between two methods of clinical measurement. Lancet 1986;i:307-310.

-30 Louis 0, Verlinde S, Thomas M, De Schepper J: Between-centre variability versus variability over time in DXA whole body measurements evaluated using a whole body phantom. Eur J Radiol 2006;58:431-434.

-31 Treuth MS, Ryan AS, Pratley RE, Rubin MA, Miller JP, Nicklas BJ: Effects of strength training on total and regional body composition in older men. J Appl Physiol 1994;77:614-620.

-32 Nindl BC, Friedl KE, Marchitelli LJ: Regional fat placement in physically fit males and changes with weight loss. Med Sci Sports Exerc 1996;28:786-793.

33 Chilibeck P, Calder A, Sale DG, Webber CE: Reproducibility of dual-energy x-ray absorptiometry. Can Assoc Radiol J 1994;45:297-302.

-34 Kelly TL, Wilson KE, Heymsfield SB: Dual energy X-ray absorptiometry body composition reference values from NHANES. PLoS One 2009;49:e7038.

-35 Sharp DS, Andrew ME, Burchfiel CM, Violanti JM, Wactawski-Wende J: Body mass index versus dual energy $\mathrm{x}$-ray absorptiometry-derived indexes: predictors of cardiovascular and diabetic disease risk factors. Am J Hum Biol 2012;24:400-405.

-36 Hull HR, Morrow ML, Heesch KC, Dinger MK, Han JL, Fields DA: Effect of the summer months on body weight and composition in college women. J Womens Health (Larchmt). 2007; 16:1510-1515.

-37 Sood A, Qualls C, Li R, Schuyler M, Beckett WS, Smith LJ, Thyagarajan B, Lewis CE, Jacobs DR; CARDIA Investigators: Lean mass predicts asthma better than fat mass among females. Eur Respir J 2011;37:65-71. 